\title{
STRATEGI PENGEMBANGAN INDUSTRI BANDENG PRESTO BU JUMIATI DI KECAMATAN JUWANA KABUPATEN PATI
}

\author{
Ani Rakhmawati, Sri Marwanti, Setyowati \\ Program Studi Agribisnis, Fakultas Pertanian, Universitas Sebelas Maret Surakarta \\ Jalan Ir. Sutami No.36 A Kentingan Surakarta 57126 Telp./Fax (0271) 637457 \\ E-mail : anye.rakhma@student.uns.ac.id
}

\begin{abstract}
The research aims to determine the cost, revenue, profit of industry milkfish presto Bu Jumiati, identify internal and external factors that affecting the development industry milkfish presto Bu Jumiati, to determine alternative strategy and strategy priority in development of industry milkfish presto Bu Jumiati. The basic method of research is descriptive with case study implementation technique. The location of the research is determined by purposive in industry milkfish presto Bu Jumiati. Analysis of the data used are (1) Analysis of cost, revenue, and profit, (2) IFE, (3) EFE, (4) SWOT, (5) QSPM. The results showed (1) Total cost of expenditure of Idr 69.043.750, the receipt of Idr 83,4 million, profit of Idr 14.356.250; (2) IFE indicates there are eight strengths and six weaknesses; (3) EFE shows there are five opportunities and five threats; (4) Alternative strategies that can be applied is to seek certificates of PIRT, halal certificate and include expiration date on product packaging, make improvements to bookkeeping management, design sales promotion with online media to increase sales and increase market development, foster strong motivation Owner of industry milkfish presto to attend information technology training and financial management; (5) A good strategic priority to apply is to obtain a PIRT certificate, a Halal certificate and include an expiration date on the product packaging.
\end{abstract}

Keywords : EFE, IFE, Profit, QSPM, SWOT

\begin{abstract}
Abstrak : Penelitian ini bertujuan untuk mengetahui besarnya biaya, penerimaan, keuntungan industri bandeng presto Bu Jumiati, mengidentifikasi faktor internal dan eksternal yang mempengaruhi pengembangan industri bandeng presto $\mathrm{Bu}$ Jumiati, menentukan alternatif strategi dan prioritas strategi dalam pengembangan industri bandeng presto $\mathrm{Bu}$ Jumiati. Metode dasar penelitian adalah deskriptif dengan teknik pelaksanaan studi kasus. Lokasi penelitian ditentukan secara purposive di industri bandeng presto $\mathrm{Bu}$ Jumiati. Analisis data yang digunakan adalah (1) Analisis biaya, keuntungan, dan penerimaan, (2) IFE, (3) EFE, (4) SWOT, (5) QSPM. Hasil penelitian menunjukkan (1) Biaya total usaha bandeng presto Bu Jumiati sebesar Rp. 69.043.750/bulan, penerimaan sebesar Rp. 83.400.000/bulan, dan keuntungan sebesar Rp. 14.356.250/bulan; (2) IFE menghasilkan delapan kekuatan dan enam kelemahan; (3) EFE menghasilkan lima peluang dan lima ancaman; (4) Alternatif strategi yang dapat diterapkan yaitu mengusahakan untuk mendapatkan sertifikat PIRT, sertifikat halal, dan mencantumkan tanggal kadaluarsa pada kemasan produk, melakukan perbaikan pada manajemen pembukuan, melakukan perancangan promosi penjualan dengan media online untuk meningkatkan penjualan dan peningkatan pengembangan pasar, menumbuhkan motivasi yang kuat pemilik industri bandeng presto untuk mengikuti pelatihan teknologi informasi dan manajemen keuangan; (5) Proritas strategi yang baik untuk diterapkan yaitu mengusahakan untuk mendapatkan sertifikat PIRT, sertifikat Halal dan mencantumkan tanggal kadaluarsa pada kemasan produk.
\end{abstract}

Kata kunci: EFE, IFE, Keuntungan, QSPM, SWOT 


\section{PENDAHULUAN}

Potensi akuakultur air payau di Indonesia dengan sistem tambak diperkirakan mencapai 931.000 ha dan dimanfaatkan potensinya untuk memelihara ikan bandeng (Chanos chanos Forsk) dan udang (Pennaeus sp.). Salah satu produk perikanan yang sering dikonsumsi oleh masyarakat adalah ikan bandeng. Ikan bandeng merupakan suatu komoditas perikanan yang memiliki rasa cukup enak, dan gurih sehingga banyak digemari masyarakat (Saparinto, 2009).

Pengolahan ikan di Indonesia sebagian besar merupakan pengolahan tradisional, karena pengolahan modern memerlukan persyaratan yang sulit dipenuhi oleh perikanan skala kecil, yaitu pasokan bahan baku yang bermutu tinggi dalam jenis dan ukuran yang seragam, dalam jumlah yang cukup banyak sesuai dengan jumlah industri. Kondisi ini menggambarkan bahwa pengolahan tradisional masih mempunyai prospek untuk dikembangkan. Prospek ini didukung oleh masih tersedianya sumberdaya ikan di pusat produksi, tingginya permintaan di tingkat konsumsi, sederhananya teknologi, serta banyaknya industri pengolahan tradisional (Heruwati, 2002).

Letak Kecamatan Juwana yang berbatasan langsung dengan pantai utara memiliki potensi perikanan yang sangat besar dan jumlah produksi perikanan tambak bandeng melimpah serta didukung dengan adanya tempat pelelangan ikan. Adanya potensi yang menguntungkan tersebut memudahkan industri bandeng presto memperoleh bahan baku yang masih segar dan berkualitas baik. Industri bandeng presto banyak berdiri dan tersebar di seluruh Kecamatan Juwana dengan jumlah pengolah bandeng presto pada tahun 2015 dapat dilihat pada Tabel 1.

Berdasarkan Tabel 1, industri pengolah bandeng presto di Kecamatan Juwana mempunyai sedikitnya 16 industri yang masih aktif menjalankan usahanya pada tahun 2015 . Industri bandeng presto Bu Jumiati merupakan salah satu industri yang memproduksi khusus pemrestoan dan berdiri 9 tahun lalu dengan pemilik bernama Ibu Jumiati sekaligus menjadi nama dari produk bandeng prestonya. Industri bandeng presto $\mathrm{Bu}$ Jumiati memiliki jumlah produksi paling banyak yaitu $100 \mathrm{~kg}$ ikan bandeng per harinya. Banyaknya jumlah produksi ini yang menjadi potensi besar untuk dikembangkan namun ada beberapa faktorfaktor yang menjadi kendala dialami oleh industri bandeng persto $\mathrm{Bu}$ Jumiati seperti sumber daya manusia yang kurang sehingga menghambat kegiatan produksi di industri milik Ibu Jumiati. Kelebihan dan kelemahan yang dimiliki industri Bu Jumiati jika dikelola dengan baik akan memberikan peluang yang bagus untuk dikembangkan, namun jika pengelolannya tidak dilakukan dengan baik maka akan menjadi ancaman.

Tabel 1. Produsen Bandeng Presto di Kecamatan Juwana Tahun 2015

\begin{tabular}{llllr}
\hline No & Nama & \multicolumn{1}{c}{ Alamat } & \multicolumn{1}{c}{ Produk Olahan } & $\begin{array}{c}\text { Jumlah Produksi } \\
\text { (Kg/Hr) }\end{array}$ \\
\hline $\mathbf{1}$ & Jumiati & Dukutalit RT 2/RW 1 & Bandeng Presto & $\mathbf{1 0 0}$ \\
2 & Warsini & Dukutalit RT 4/RW 1 & Bandeng Presto & 50 \\
3 & Samira & Doropayung & Bandeng Presto & 50 \\
4 & Kuntari & Growong Kidul & Bandeng Presto & 50 \\
5 & Wadi & Dukutalit RT 4/RW 1 & Bandeng Presto & 30 \\
6 & Sukini & Dukutalit RT 4/RW 1 & Bandeng Presto & 30 \\
7 & Suroto & Dukutalit RT 4/RW 1 & Bandeng Presto & 30 \\
8 & Masrur & Alasdowo RT 2/RW 4 & Bandeng Presto & 30 \\
9 & Karyati & Mangunlegi RT 1/RW 2 & Bandeng Presto, pepes & 30 \\
10 & Suparni & Dukutalit RT 3/RW 2 & Bandeng Presto & 25 \\
11 & Safaati & Dukutalit RT 3/RW 2 & Bandeng Presto, pepes, krupuk & 20 \\
12 & Suparti & Dukutalit RT 3/RW 2 & Bandeng Presto & 20 \\
13 & Suradi & Dukutalit RT 3/RW 2 & Bandeng Presto & 20 \\
14 & Kardi & Doropayung & Bandeng Presto & 15 \\
15 & Wati & Raci & Bandeng Presto & 10 \\
16 & Yasir Tri & Raci & Bandeng Presto & 10 \\
\hline
\end{tabular}

Sumber : Dinas Kelautan dan Perikanan Kabupaten Pati, 2016 
Berdasarkan latar belakang tersebut maka tujuan penelitian ini adalah (1) untuk mengetahui besarnya biaya, penerimaan, keuntungan industri bandeng presto Bu Jumiati, (2) mengidentifikasi faktor internal dan eksternal yang mempengaruhi pengembangan industri bandeng presto $\mathrm{Bu}$ Jumiati, (3) menentukan alternatif strategi (4) prioritas strategi dalam pengembangan industri bandeng presto Bu Jumiati.

\section{METODE PENELITIAN}

Metode dasar penelitian ini adalah metode deskriptif dengan teknik pelaksanaan studi kasus (Surakhmad, 2004). Pemilihan lokasi penelitian dilakukan secara purposive (sengaja) pada industri bandeng presto $\mathrm{Bu}$ Jumiati di Desa Dukutalit Kecamatan Juwana Kabupaten Pati, dengan pertimbangan berdasarkan Tabel 1 industri bandeng presto $\mathrm{Bu}$ Jumiati memiliki jumlah produksi paling banyak yaitu $100 \mathrm{~kg}$ ikan bandeng setiap harinya. Tingginya jumlah produksi ini yang menjadi pertimbangan untuk mengambil lokasi di industri bandeng presto $\mathrm{Bu}$ Jumiati karena dengan jumlah produksi yang tinggi akan memiliki keberlanjutan dalam usahanya dan waktu penelitian ini dilaksanakan pada tanggal 2-31 Januari 2017.

Informan kunci pada penelitian ini dilakukan secara sengaja (purposive) dengan pertimbangan bahwa orang tersebut dianggap paling mengetahui informasi yang diharapkan, yang paling berpengaruh sehingga memudahkan peneliti menggali informasi yang dibutuhkan. Informan kunci yang dipilih dalam penelitian ini adalah pemilik industri bandeng presto yaitu Ibu Jumiati, karyawan, pedagang, konsumen rumahtangga, pesaing dan Dinas Kelautan dan Perikanan Kabupaten Pati. Data yang digunakan adalah data primer dan sekunder. Pengumpulan data dengan observasi, wawancara, pencatatan, dan dokumentasi.

Metode analisis data yang digunakan adalah Analisis biaya, penerimaan, dan keuntungan, Matriks IFE dan EFE, Matriks Internal-Eksternal (IE), SWOT serta menggunakan Matriks QSPM.

\section{HASIL DAN PEMBAHASAN}

Industri bandeng presto $\mathrm{Bu}$ Jumiati merupakan industri yang memproduksi bandeng presto.
Industri ini berdiri sejak tahun 2008, dalam mendirikan usaha bandeng presto awalnya hanya bermodalkan panci presto berukuran kecil yang diperoleh dari pemberian saudaranya. Kondisi perekonomian keluarga Ibu Jumiati yang memburuk pada saat itu membuat Ibu Jumiati mencari tambahan penghasilan sendiri dengan memanfaatkan panci presto pemberian saudaranya untuk membuka usaha bandeng presto. Awalnya Ibu Jumiati hanya memproduksi $5 \mathrm{~kg}$ bandeng.

Industri bandeng presto $\mathrm{Bu}$ Jumiati beroperasi mulai jam 8 pagi hingga 3 sore dan berproduksi setiap hari dengan rata-rata jumlah produksi mencapai $100 \mathrm{~kg}$ ikan bandeng segar/hari. Bahan baku ikan bandeng diperoleh Ibu Jumiati dari pasar Porda yang merupakan tempat pelelangan ikan, letaknya berada di Kecamatan Juwana. Harga bandeng presto $\mathrm{Bu}$ Jumiati yaitu Rp. 4.500; (1 dus kecil isi 2 bandeng presto dengan berat \pm 140 gram untuk diambil pedagang yang nantinya dijual kembali), dan untuk konsumen langsung harganya mulai Rp.10.000; (1 dus ukuran kecil isi dua bandeng presto dengan berat \pm 200 gram), Rp. 12.000; (1 dus ukuran sedang isi dua bandeng presto dengan berat \pm 240 gram) dan Rp. 15.000; (1 dus ukuran besar isi dua bandeng presto dengan berat \pm 300 gram).

\section{Biaya, Penerimaan, dan Keuntungan}

Biaya dalam penelitian ini adalah seluruh biaya yang dikeluarkan untuk proses pembuatan bandeng presto $\mathrm{Bu}$ Jumiati yang terdiri dari biaya tetap dan biaya variabel. Biaya total adalah hasil dari penjumlahan seluruh biaya tetap dan biaya variabel yang dikeluarkan selama proses produksi. Besarnya biaya total untuk proses produksi bandeng presto $\mathrm{Bu}$ Jumiati selama bulan Januari 2017 dapat dilihat pada Tabel 2.

Tabel 2. Analisis Biaya Total Industri Bandeng Bu Jumiati Bulan Januari 2017

\begin{tabular}{llr}
\hline No & Jenis Biaya & Biaya (Rp/Bulan) \\
\hline 1 & Biaya Tetap & 549.250 \\
2 & Biaya Variabel & 68.494 .500 \\
\hline & Total & 69.043 .750 \\
\hline
\end{tabular}

Sumber: Analisis Data Primer, 2017

Berdasarkan Tabel 2, dapat diketahui bahwa biaya total yang harus dikeluarkan 
Ani R., Sri Marwanti, Setyowati: Strategi Pengembangan Industri Bandeng Presto ...

Tabel 3. Penerimaan Industri Bandeng Bu Jumiati Bulan Januari 2017

\begin{tabular}{|c|c|c|c|c|}
\hline No & Uraian Penerimaan & $\begin{array}{c}\text { Harga satuan } \\
\text { (Rp/kardus) }\end{array}$ & Jumlah (kardus) & Penerimaan/Bulan \\
\hline 1 & Pedagang & 4.500 & 6.000 & 27.000 .000 \\
\hline 2 & Konsumen kardus kecil & 10.000 & 1.500 & 15.000 .000 \\
\hline 3 & Konsumen kardus sedang & 12.000 & 1.200 & 14.400 .000 \\
\hline \multirow[t]{2}{*}{4} & Konsumen kardus besar & 15.000 & 1.800 & 27.000 .000 \\
\hline & Total & & 10.500 & 83.400 .000 \\
\hline
\end{tabular}

Sumber: Analisis Data Primer, 2017

dalam proses produksi per bulan yaitu sebesar Rp. 69.043.750. Biaya terbesar dalam industri bandeng presto $\mathrm{Bu}$ Jumiati berasal dari biaya variabel yaitu terbesar Rp. 68.494.500, hal ini dikarenakan banyaknya jumlah produksi bandeng presto dan tingginya harga bahanbahan yang digunakan dalam proses pembuatan bandeng presto, sedangkan biaya tetap sebesar Rp. 549.250.

Hasil analisis penerimaan usaha bandeng presto $\mathrm{Bu}$ Jumiati disajikan pada Tabel 3 . Penerimaan dihitung dengan mengaliokan jumlah produk bandeng yang dihasilkan dengan harga bandeng masing-masing kemasan. Berdasarkan Tabel 3 diketahui bahwa total penerimaan pada bulan Januari 2017 dari industri bandeng presto $\mathrm{Bu}$ Jumiati adalah sebesar Rp. 83.400.000. Penerimaan terbesar berasal dari pedagang dengan berat \pm 140 gram dan harga satuan Rp. 4.500 sebanyak 6.000 kardus per bulan.

Penerimaan terbesar lainnya diperoleh dari penjualan langsung kepada konsumen jenis kardus besar dengan berat \pm 300 gram dan harga satuan Rp. 15.000 per kardus terjual sebanyak 1.800 kardus. Keuntungan industri ini adalah selisih antara penerimaan yang diperoleh dengan semua biaya total industri dalam waktu satu bulan seperti dalam Tabel 4 .

Tabel 4. Keuntungan Industri Bandeng Bu Jumiati Bulan Januari 2017

\begin{tabular}{llr}
\hline No & Uraian & Biaya (Rp/Bulan) \\
\hline 1 & Penerimaan & 83.400 .000 \\
2 & Biaya Total & 69.043 .750 \\
3 & Keuntungan & 14.356 .250 \\
\hline
\end{tabular}

Sumber: Analisis Data Primer, 2017
Tabel 4 menunjukkan bahwa keuntungan industri bandeng presto Bu Jumiati pada bulan Januari 2017 adalah sebesar Rp. 14.356.250. Keuntungan ini diperoleh dari penerimaan sebesar Rp. 83.400.000 dikurangi dengan biaya total sebesar Rp. 69.043 .750 (biaya tetap dan biaya variabel).

\section{Faktor Internal dan Eksternal dalam Pengembangan Industri Bandeng Presto Bu Jumiati}

Faktor internal merupakan faktor yang berasal dari dalam suatu industri dan dapat dikendalikan oleh industri tersebut. Faktor internal industri bandeng presto $\mathrm{Bu}$ Jumiati adalah faktor-faktor yang terkait dengan sumberdaya manusia, produksi dan operasi, keuangan dan pemasaran yang terdapat didalam industri bandeng presto Bu Jumiati. Identifikasi faktor internal menghasilkan 8 faktor kekuatan dan 6 faktor kelemahan.

Faktor eksternal industri bandeng presto Bu Jumiati terdiri 5 faktor peluang dan 5 faktor ancaman. Faktor tersebut merupakan faktor yang mencakup hal-hal dari luar yang memberi pengaruh atau dampak terhadap keberlangsungan usaha bandeng presto $\mathrm{Bu}$ Jumiati yangpada umumnya tidak dapat dikontrol oleh produsen. Faktor-faktor eksternal yang diidentifikasi meliputi faktor teknologi informasi, sosial budaya, kondisi perekonomian, pesaing, konsumen dan kebijakan pemerintah Kabupaten Pati.

Hasil identifikasi faktor internal dan eksternal usaha bandeng pesto $\mathrm{Bu}$ Jumiati disajikan pada Tabel 5 dan Tabel 6. 
Tabel 5. Faktor Internal Industri Bandeng Presto Bu Jumiati

\begin{tabular}{|c|c|c|c|}
\hline \multicolumn{2}{|r|}{ Kekuatan } & \multicolumn{2}{|r|}{ Kelemahan } \\
\hline 1 & $\begin{array}{l}\text { Pemilik mempunyai relasi dengan banyak } \\
\text { pedagang }\end{array}$ & 1 & $\begin{array}{l}\text { Belum memiliki sertifikat PIRT, sertifikat Halal } \\
\text { dan mencantumkan tanggal kadaluarsa pada } \\
\text { kemasan produk }\end{array}$ \\
\hline 2 & Tidak menggunakan bahan pengawet & 2 & $\begin{array}{l}\text { Sistem pembukuan atau sistem akuntansi } \\
\text { keuangan masih sederhana }\end{array}$ \\
\hline 3 & Sarana prasarana produksi modern & 3 & Modal terbatas \\
\hline 4 & Harga terjangkau & 4 & $\begin{array}{l}\text { Jumlah karyawan tidak seimbang dengan beban } \\
\text { kerja }\end{array}$ \\
\hline 5 & $\begin{array}{l}\text { Lokasi toko menjadi satu dengan tempat } \\
\text { produksi dan strategis }\end{array}$ & 5 & Promosi kurang optimal \\
\hline 6 & Karyawan bagian penggorengan terampil & 6 & $\begin{array}{l}\text { Kurangnya motivasi pengusaha untuk mengikuti } \\
\text { kebijakan pemerintah }\end{array}$ \\
\hline 7 & Segmen pasar untuk semua kalangan & & \\
\hline 8 & $\begin{array}{l}\text { Bandeng Juwana memiliki keunggulan } \\
\text { tidak berbau lumpur }\end{array}$ & & \\
\hline
\end{tabular}

Sumber: Analisis Data Primer, 2017

Tabel 6. Faktor Eksternal Industri Bandeng Presto Bu Jumiati

\begin{tabular}{|c|c|c|c|}
\hline \multicolumn{2}{|r|}{ Peluang } & \multicolumn{2}{|r|}{ Ancaman } \\
\hline 1 & $\begin{array}{l}\text { Bahan baku selalu tersedia, mudah } \\
\text { diperoleh dan berkualitas }\end{array}$ & 1 & Fluktuasi harga bahan baku ikan ba \\
\hline 2 & Adanya peluang pasar yang masih luas & 2 & Tingkat persaingan tinggi \\
\hline 3 & $\begin{array}{l}\text { Permintaan konsumen bandeng presto } \\
\text { meningkat saat liburan nasional maupun } \\
\text { liburan sekolah }\end{array}$ & 3 & $\begin{array}{l}\text { Pesaing memanfaatkan perkembangan teknologi } \\
\text { informasi }\end{array}$ \\
\hline 4 & $\begin{array}{l}\text { Berkembangnya tren hidup sehat dan } \\
\text { praktis di masyarakat }\end{array}$ & 4 & Merk produk pesaing lebih dikenal masyarakat \\
\hline 5 & $\begin{array}{l}\text { Adanya pelatihan, pembinaan dan bantuan } \\
\text { dari Pemerintah Kabupaten Pati }\end{array}$ & $J$ & $\begin{array}{l}\text { Pesaing utama memiliki banyak variasi produk } \\
\text { olahan dari bandeng }\end{array}$ \\
\hline
\end{tabular}

Sumber: Analisis Data Primer, 2017

Strategi Pengembangan Industri Bandeng Presto Bu Jumiati

Matriks IFE digunakan untuk menganalisis faktor internal dan mengklasifikasikan menjadi kekuatan dan kelemahan bagi industri bandeng presto Bu Jumiati. Matriks (EFE) menganalisis faktor eksternal pada industri bandeng presto $\mathrm{Bu}$ Jumiati yang terbagi menjadi dua bagian yaitu peluang dan ancaman.

Berdasarkan hasil dari Matriks IFE dan EFE, maka dapat disusun Matriks IE (InternalEksternal Matrix) yang dapat memposisikan industri bandeng presto $\mathrm{Bu}$ Jumiati dalam tampilan 9 sel. Setelah itu dilakukan analisis SWOT untuk merumuskan alternative strategi perusahaan untuk memaksimalkan peranan faktor kekuatan dan pemanfaatan peluang sehingga berperan sebagai alat untuk meminimalisasi kelemahan yang terdapat dalam tubuh perusahaan dan menekan dampak ancaman yang timbul dan harus dihadapi. Setelah dianalisis menggunakan matriks SWOT maka akan diperoleh beberapa strategi. Hasil dari strategi yang telah dirumuskan pada analisis SWOT kemudian akan dipilih satu strategi yang dapat dijadikan sebagai prioritas strategi untuk pengembangan industri bandeng presto Bu Jumiati. Pemilihan prioritas strategi pengembangan industry bandeng presto $\mathrm{Bu}$ Jumiati dilakukan melalui analisis matriks QSP.

Matriks (IFE) Internal Factor Evaluation, matriks (EFE) Eksternal Factor Evaluation, Matriks IE (Internal-Eksternal Matrix), SWOT, dan matriks QSP disajikan pada tabel dan gambar berikut ini. 
Tabel 7. Matriks IFE Pengembangan Industri Bandeng Presto Bu Jumiati

\begin{tabular}{|c|c|c|c|}
\hline Faktor internal & Bobot & Rating & Skor Bobot \\
\hline \multicolumn{4}{|l|}{ Kekuatan } \\
\hline 1. Pemilik mempunyai relasi dengan banyak pedagang & 0,062 & 4 & 0,247 \\
\hline 2. Tidak menggunakan bahan pengawet & 0,048 & 3 & 0,156 \\
\hline 3. Sarana prasarana produksi modern & 0,062 & 3 & 0,200 \\
\hline 4. Harga terjangkau & 0,048 & 4 & 0,192 \\
\hline 5. Lokasi toko menjadi satu dengan tempat produksi dan strategis & 0,058 & 3 & 0,189 \\
\hline 6. Karyawan bagian penggorengan terampil & 0,062 & 3 & 0,200 \\
\hline 7. Segmen pasar untuk semua kalangan & 0,072 & 4 & 0,270 \\
\hline $\begin{array}{l}\text { 8. Bandeng Juwana memiliki keunggulan tidak berbau lumpur } \\
\text { Kelemahan }\end{array}$ & 0,123 & 4 & 0,493 \\
\hline $\begin{array}{l}\text { 1. Belum memiliki sertifikat PIRT, sertifikat halal dan } \\
\text { mencantumkan tanggal kadaluarsa pada kemasan produk }\end{array}$ & 0,144 & 2 & 0,288 \\
\hline $\begin{array}{l}\text { 2. Sistem pembukuan atau sistem akuntansi keuangan masih } \\
\text { sederhana }\end{array}$ & 0,051 & 2 & 0,077 \\
\hline 3. Modal terbatas & 0,045 & 2 & 0,078 \\
\hline 4. Jumlah karyawan tidak seimbang dengan beban kerja & 0,089 & 1 & 0,111 \\
\hline 5. Promosi kurang optimal & 0,088 & 1 & 0,111 \\
\hline $\begin{array}{l}\text { 6. Kurangnya motivasi pengusaha untuk mengikuti kebijakan } \\
\text { pemerintah }\end{array}$ & 0,048 & 2 & 0,072 \\
\hline Jumlah & $\mathbf{1 , 0 0}$ & & 2,68 \\
\hline
\end{tabular}

Sumber: Analisis Data Primer, 2017

Tabel 8. Matriks EFE Pengembangan Industri Bandeng Presto Bu Jumiati

\begin{tabular}{llcc}
\hline Faktor eksternal & Bobot & Rating & Skor Bobot \\
\hline $\begin{array}{l}\text { Peluang } \\
\begin{array}{l}\text { 1. Bahan baku selalu tersedia, mudah diperoleh } \\
\quad \text { dan berkualitas }\end{array}\end{array}$ & 0,074 & 3 & 0,223 \\
$\begin{array}{l}\text { 2. Adanya peluang pasar yang masih luas } \\
\text { 3. Permintaan konsumen bandeng presto } \\
\quad \text { meningkat saat liburan nasional maupun liburan }\end{array}$ & 0,090 & 2 & 0,136 \\
$\quad$ sekolah & 0,170 & 4 & 0,638 \\
$\begin{array}{l}\text { 4. Berkembangnya tren hidup sehat dan praktis di } \\
\quad \text { masyarakat }\end{array}$ & 0,069 & 2 & 0,138 \\
$\begin{array}{l}\text { 5. Adanya pelatihan, pembinaan dan bantuan dari } \\
\quad \text { Pemerintah Kabupaten Pati }\end{array}$ & 0,085 & 1 & 0,106 \\
Ancaman & & & \\
$\begin{array}{l}\text { 1. Fluktuasi harga bahan baku ikan bandeng segar } \\
\text { 2. Tingkat persaingan tinggi }\end{array}$ & 0,080 & 3 & 0,199 \\
$\begin{array}{l}\text { 3. Pesaing memanfaatkan perkembangan } \\
\text { teknologi informasi }\end{array}$ & 0,085 & 3 & 0,213 \\
$\begin{array}{l}\text { 4. Merk produk pesaing lebih dikenal masyarakat } \\
\text { 5. Pesaing utama memiliki banyak variasi produk } \\
\quad \text { olahan dari bandeng }\end{array}$ & 0,149 & 4 & 0,559 \\
Jumlah & 0,128 & 2 & 0,138 \\
\hline
\end{tabular}

Sumber: Analisis Data Primer, 2017 


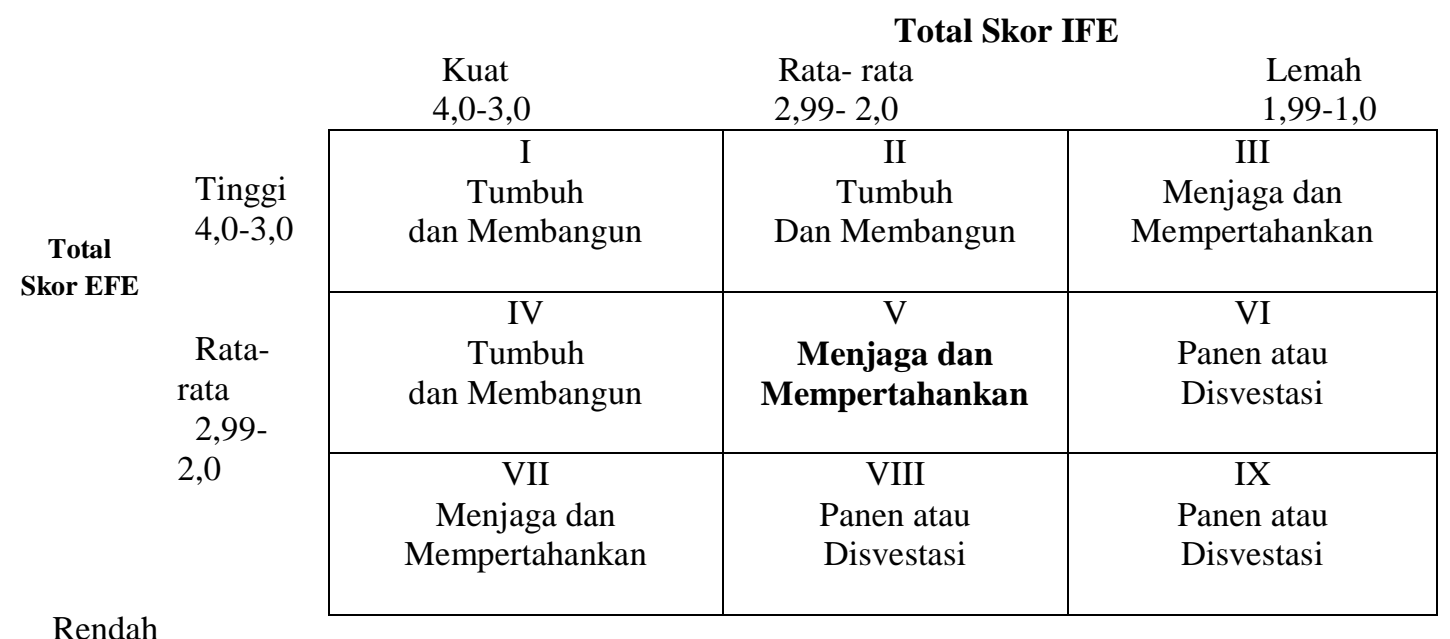

$1,99-1,0$

Gambar 1. Matriks IE Industri Bandeng Presto Bu Jumiati

Kekuatan utama dalam pengembangan industri bandeng presto $\mathrm{Bu}$ Jumiati dengan skor tertinggi 0,493 adalah bandeng Juwana memiliki keunggulan tidak berbau lumpur. Kelemahan utama dalam pengembangan industri bandeng presto Bu Jumiati dengan skor tertinggi 0,288 adalah belum memiliki sertifikat PIRT, sertifikat halal dan mencantumkan tanggal kadaluarsa pada kemasan produk.

Analisis faktor-faktor internal menghasilkan angka 2,68. Berdasarkan nilai skor matriks IFE tersebut mengidentifikasikan bahwa faktor internal berada dalam posisi kuat karena berada di atas 2,5 (David, 2011). Hal ini mengidentifikasikan bahwa industri bandeng presto $\mathrm{Bu}$ Jumiati telah mampu memanfaatkan kekuatan untuk mengatasi kelemahan dalam memasarkan produknya. Faktor peluang dan ancaman adalah faktor yang menggambarkan kondisi eksternal dalam strategi pengembangan industri bandeng presto $\mathrm{Bu}$ Jumiati. Peluang utama dalam pengembangan industri bandeng presto $\mathrm{Bu}$ Jumiati dengan skor 0,638 yaitu permintaan konsumen bandeng presto meningkat saat liburan nasional maupun liburan sekolah. Ancaman utama dalam pengembangan industri bandeng presto $\mathrm{Bu}$ Jumiati dengan skor 0,559 yaitu pesaing memanfaatkan perkembangan teknologi informasi.

Berdasarkan perolehan hasil IFE dan EFE, pada sumbu $x$ dari Matriks IE, skor bobot IFE bandeng presto Bu Jumiati adalah sebesar 2,78 yang menunjukkan posisi internal bandeng presto Bu Jumiati yang sedang. Pada sumbu $y$ dari Matriks IE, skor bobot EFE bandeng presto $\mathrm{Bu}$ Jumiati adalah sebesar 2,61 yang menunjukkan posisi eksternal bandeng presto yang sedang. Maka posisi industri bandeng presto Bu Jumiati seperti dalam Gambar 1 .

Berdasarkan gambar di atas, diketahui bahwa industri bandeng presto $\mathrm{Bu}$ Jumiati berada pada sel $\mathrm{V}$, yaitu menjaga dan mempertahankan. Pada sel ini, strategi yang dapat dilakukan adalah strategi intensif yaitu penetrasi pasar dan strategi pengembangan produk.

Menurut Jamshidi et al., (2012) matriks SWOT terdapat kekuatan, kelemahan, peluang dan ancaman kemudian dikembangkan menjadi 4 strategi yaitu SO, OW, ST, dan WT. Implementasi strategi SO, organisasi berusaha untuk membuat peluang eksternal dengan memanfaatkan kekuatan internal. Tujuan dari strategi OW yaitu untuk membantu perusahaan memperbaiki kelemahan internal dengan menggunakan peluang eksternal. Implementasi strategi ST, perusahaan berusaha untuk meminimalkan ancaman di faktor eksternal dengan menggunakan kekuatan internal perusahaan. Pada strategi WT, perusahaan mengambil posisi bertahan sehingga mereka dapat meminimalisir ancaman dari faktor eksternal dengan menggunakan kekuatan yang dimiliki perusahaan dengan mengacu pada posisi perusahaan di matriks IE.

Berdasarkan matriks SWOT pada Tabel 9, ada tujuh alternatif strategi dalam pengembangan industri bandeng presto $\mathrm{Bu}$ Jumiati, strategi tersebut antara lain: Menjaga 
serta meningkatkan kualitas produk untuk mempertahankan pelanggan lama dan memperoleh pelanggan baru, mengusahakan untuk mendapatkan sertifikat PIRT dan sertifikat halal dan mencantumkan tanggal kadaluarsa, melakukan perbaikan pada manajemen pembukuan, promosi menarik seperti promo potongan harga, pemberian bonus dan tester bagi kosumen, mempertahankan harga jual produk yang terjangkau untuk menjaga loyalitas konsumen,

Tabel 9. Matriks SWOT Industri Bandeng Presto Bu Jumiati

\begin{tabular}{|c|c|c|}
\hline Faktor Eksternal & 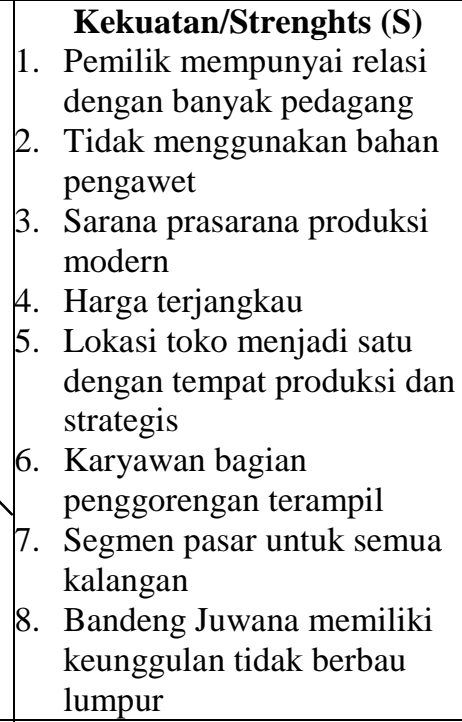 & $\begin{array}{l}\text { Kelemahan/Weakness (W) } \\
\text { 1. } \text { Belum memiliki sertifikat PIRT, } \\
\text { sertifikat halal dan mencantumkan } \\
\text { tanggal kadaluarsa pada kemasan } \\
\text { produk } \\
\text { 2. Sistem pembukuan atau sistem } \\
\text { akuntansi keuangan masih } \\
\text { sederhana } \\
\text { 3. } \text { Modal terbatas } \\
\text { 4. Jumlah karyawan tidak seimbang } \\
\text { dengan beban kerja } \\
\text { 5. Promosi kurang optimal } \\
\text { 6. } \text { Kurangnya motivasi pengusaha } \\
\text { untuk mengikuti kebijakan } \\
\text { pemerintah }\end{array}$ \\
\hline 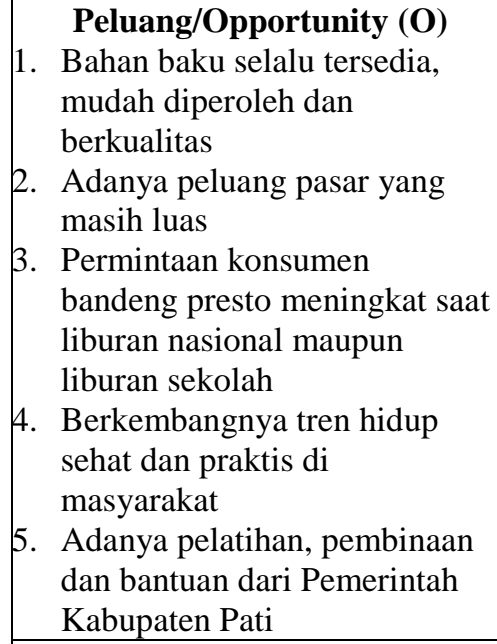 & \begin{tabular}{|l} 
Strategi S-O \\
1. \\
Menjaga serta \\
meningkatkan kualitas \\
produk untuk \\
mempertahankan pelanggan \\
lama dan memperoleh \\
pelanggan baru \\
(S1,S2,S3,S6, O1,O3)
\end{tabular} & \begin{tabular}{|l} 
Strategi W-O \\
1. \\
Mengusahakan untuk \\
mendapatkan sertifikat PIRT, \\
sertifikat Halal dan \\
mencantumkan tanggal kadaluarsa \\
pada kemasan (W1,W5, O2,O4) \\
2. \\
Melakukan perbaikan pada \\
manajemen pembukuan \\
(W2,W4,O2,O3,O5)
\end{tabular} \\
\hline \begin{tabular}{|l}
\multicolumn{1}{c}{ Ancaman/Threats (T) } \\
1. \\
Fluktuasi harga bahan baku \\
ikan bandeng segar \\
2. Tingkat persaingan tinggi \\
3. Pesaing memanfaatkan \\
perkembangan teknologi \\
informasi \\
4. Merk produk pesaing lebih \\
dikenal masyarakat \\
5. $\begin{array}{l}\text { Pesaing utama memiliki } \\
\text { banyak variasi produk olahan } \\
\text { dari bandeng }\end{array}$ \\
\end{tabular} & \begin{tabular}{|l} 
Strategi S-T \\
1. \\
Melakukan upaya promosi \\
menarik seperti promo \\
potongan harga, pemberian \\
bonus dan tester bagi \\
kosumen (S4,S5,S7,T2,T5) \\
2. \\
Mempertahankan harga jual \\
produk yang terjangkau \\
untuk menjaga loyalitas \\
konsumen (S4,S8,T1, \\
T2,T5)
\end{tabular} & \begin{tabular}{|l} 
Strategi W-T \\
1. \\
Melakukan perancangan promosi \\
penjualan dengan media online \\
untuk meningkatkan penjualan \\
dan peningkatan pengembangan \\
pasar (W3, W5,T2,T3,T4) \\
2. Menumbuhkan motivasi yang kuat \\
pemilik industri bandeng presto \\
untuk mengikuti pelatihan \\
teknologi informasi dan \\
manajemen keuangan \\
(W2,W3,W4,W6, T2,T3)
\end{tabular} \\
\hline
\end{tabular}

Sumber : Analisis Data Primer, 2017 
Tabel 10. Matriks QSP Industri Bandeng Presto Bu Jumiati

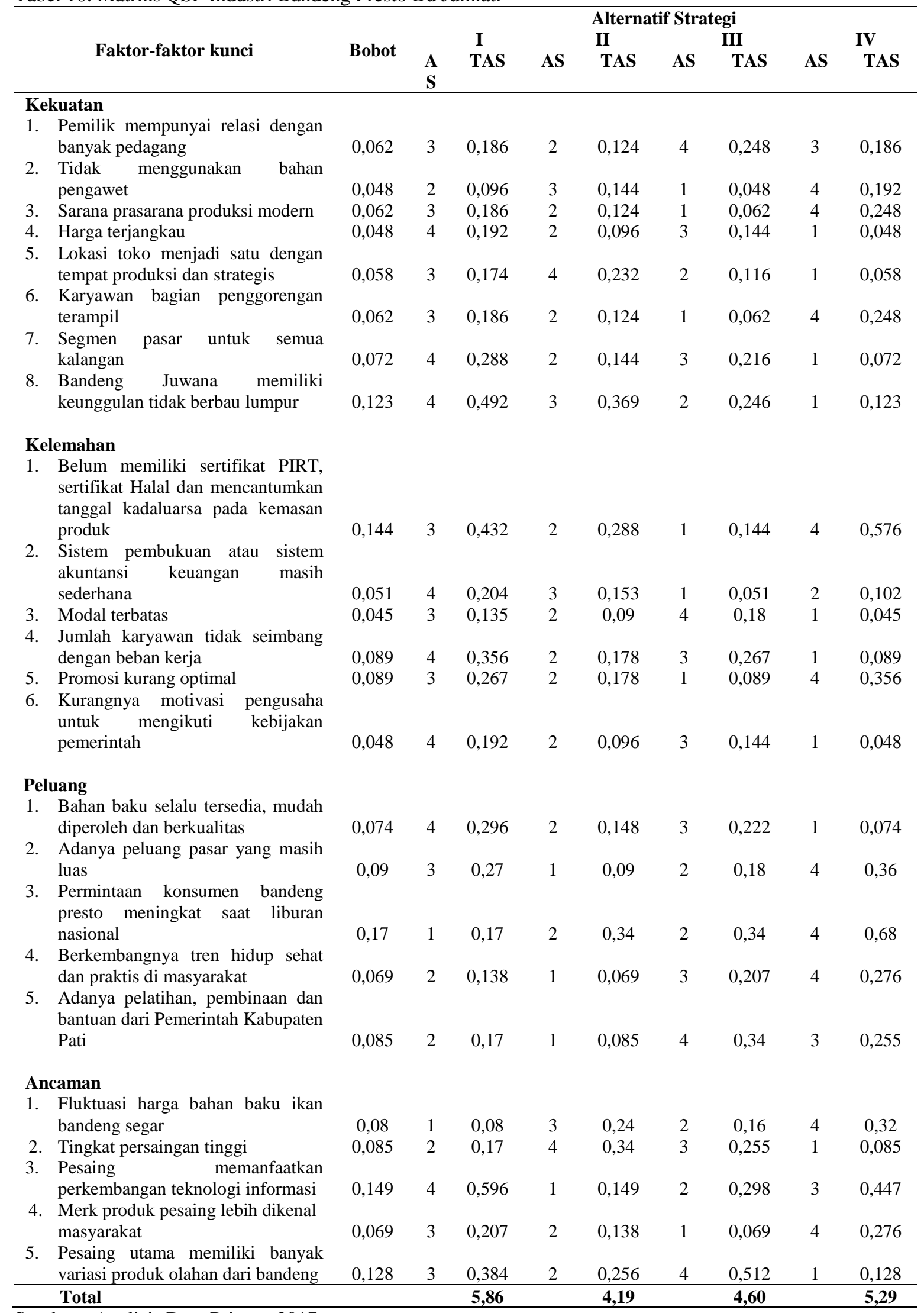

Sumber : Analisis Data Primer, 2017 
melakukan perancangan promosi penjualan dengan media online untuk meningkatkan penjualan dan peningkatan pengembangan pasar dan menumbuhkan motivasi yang kuat pemilik industri bandeng presto untuk mengikuti pelatihan teknologi informasi dan manajemen keuangan.

QSPM merupakan salah satu teknik analisis yang didesain untuk menentukan daya tarik relatif dari beberapa alternatif. QSPM secara konseptual menentukan daya tarik relatif dari beberapa strategi yang dibentuk dari faktor penentu keberhasilan yaitu faktor internal dan eksternal. Daya tarik relatif masing-masing strategi ditentukan dengan melihat dampak atau pengaruhnya terhadap masing-masing faktor internal dan eksternal (Asih dan Kevin, 2013). Berikut ini adalah matriks QSP untuk pengembangan industri bandeng presto $\mathrm{Bu}$ Jumiati yang dapat dilihat pada Tabel 10 .

Berdasarkan hasil analisis QSPM, total nilai tertinggi adalah strategi I sebesar 5,86. Strategi pertama merupakan strategi mengusahakan untuk mendapatkan sertifikat PIRT dan sertifikat halal dan memberikan tanggal kadaluarsa pada kemasan produk. Strategi dengan total nilai daya tarik tertinggi mengindikasikan bahwa strategi tersebut terpilih sebagai strategi terbaik yang dapat dilaksanakan terlebih dulu dalam pengembangan industri bandeng presto $\mathrm{Bu}$ Jumiati. Selain strategi tersebut, strategi strategi kedua yang dapat dilakukan adalah strategi IV dengan total nilai daya tarik sebesar 5,29. Strategi III dengan total nilai daya tarik sebesar 4,60, dan strategi II dengan total nilai daya tarik sebesar 4,19.

\section{KESIMPULAN DAN SARAN}

\section{Kesimpulan}

Berdasarkan hasil penelitian strategi pengembangan industri bandeng presto $\mathrm{Bu}$ Jumiati di Kecamatan Juwana Kabupaten Pati, maka diperoleh kesimpulan sebagai berikut (1) Industri bandeng presto $\mathrm{Bu}$ Jumiati di Kecamatan Juwana Kabupaten Pati dijalankan dengan biaya tetap sebesar Rp. 549.250, sedangkan biaya variabel pada bulan Januari 2017 yaitu sebesar Rp. 68.494.500, penerimaan sebesar Rp 83.400.000/bulan serta keuntungan industri bandeng presto Bu Jumiati pada bulan Januari 2017 adalah sebesar Rp. 14.356.250/bulan. (2) Faktor internal yang menjadi kekuatan utama dari bandeng presto $\mathrm{Bu}$ Jumiati adalah bandeng Juwana memiliki keunggulan tidak berbau lumpur sedangkan yang menjadi kelemahan utama dari bandeng presto $\mathrm{Bu}$ Jumiati adalah belum memiliki sertifikat PIRT, sertifikat halal dan mencantumkan tanggal kadaluarsa pada kemasan produk. Faktor eksternal yang dapat dimiliki sebagai peluang utama dari bandeng presto Bu Jumiati adalah permintaan konsumen bandeng presto meningkat saat liburan nasional maupun liburan sekolah dan yang menjadi ancaman bagi bandeng presto $\mathrm{Bu}$ Jumiati adalah pesaing memanfaatkan perkembangan teknologi informasi. (3) Posisi industri bandeng presto $\mathrm{Bu}$ Jumiati berada pada sel $\mathrm{V}$, dengan strategi yang dapat diterapkan yaitu menjaga dan mempertahankan melalui alternatif strategi penetrasi pasar dan pengembangan produk. Oleh karena itu, dapat direkomendasikan tujuh alternatif strategi antara lain menjaga serta meningkatkan kualitas produk untuk mempertahankan pelanggan lama dan memperoleh pelanggan baru, mengusahakan untuk mendapatkan sertifikat PIRT dan sertifikat halal dan mencantumkan tanggal kadaluarsa pada kemasan produk, melakukan perbaikan pada manajemen pembukuan, promosi menarik seperti promo potongan harga, pemberian bonus dan tester bagi kosumen, mempertahankan harga jual produk yang terjangkau untuk menjaga loyalitas konsumen, melakukan perancangan promosi penjualan dengan media online untuk meningkatkan penjualan dan peningkatan pengembangan pasar, menumbuhkan motivasi yang kuat pemilik industri bandeng presto untuk mengikuti pelatihan teknologi informasi dan manajemen keuangan. (4) prioritas strategi yang dapat dilakukan oleh industri bandeng presto $\mathrm{Bu}$ Jumiati adalah dengan strategi mengusahakan untuk mendapatkan sertifikat PIRT, sertifikat halal dan mencantumkan tanggal kadaluarsa pada kemasan produk dengan total nilai daya tarik tertinggi (STAS) sebesar 5,86.

\section{Saran}

Bedasarkan prioritas strategi yang diperoleh, maka saran untuk pengembangan industri bandeng presto $\mathrm{Bu}$ Jumiati adalah (1) perlu adanya sistem pembukuan secara tertib, 
mengingat selama ini tidak ada sistem pembukuan dalam industri bandeng presto $\mathrm{Bu}$ Jumiati. (2) perlu adanya penyuluhan dari pemerintah Kabupaten Pati kepada Ibu Jumiati untuk menumbuhkan motivasi pemilik industri dalam memanfaatkan penggunaan teknologi informasi untuk memasarkan produk berbasis online (3) perlu dilakukan pengembangan produk melalui inovasi kemasan produk dengan cara bandeng presto dikemas menggunakan vacum agar lebih awet dan tahan lama. (4) perlu dilakukan pendamping dari pihak pemerintah Kabupaten Pati untuk mendampingi industri bandeng presto $\mathrm{Bu}$ Jumiati dalam mengurus perijinan PIRT dan sertifikat halal sehingga prioritas strategi untuk industri bandeng presto $\mathrm{Bu}$ Jumiati dapat dijalankan dengan baik.

\section{DAFTAR PUSTAKA}

Asih And Kevin J. 2013. Determining Strategies Based on Strategic Position Analysis in Small and Medium Enterprises. International Journal of
Information and Education Technology, Vol. 3 No. 4.

David, F R. 2011. Manajemen Stategis Konsep, Terjemahan. Edisi 12 Buku 1. Salemba Empat. Jakarta.

Dinas Kelautan dan Perikanan. 2016. Data Pengolah Bandeng Presto di Kecamatan Juwana Tahun 2015. Pati.

Heruwati, E.S. 2002. Pengolahan Ikan Secara Tradisional: Prospek dan Peluang Pengembangan. Jurnal litbang pertanian. Vol. 21No. 3 .

Jamshidi, Sajjadi, Habib. 2012. Swot Analysis of Strategic Position of Cycling Federation in Iran. International Journal of Academic Research in Bussinesdan Social Sciences. Vol.2 No.5.

Saparinto, C. 2009. Budidaya Ikan di Kolam Terpal. Lewis Publisher. Jakarta.

Surakhmad. 2004. Pengantar Penelitian Ilmiah. Tarsito. Bandung. 